Article

\title{
Phosphate-Based Ultrahigh Molecular Weight Polyethylene Fibers for Efficient Removal of Uranium from Carbonate Solution Containing Fluoride Ions
}

\author{
Rong $\mathrm{Li}^{1}$, Yuna $\mathrm{Li}^{1,2}$, Maojiang Zhang ${ }^{1,3}$, Zhe Xing ${ }^{1}$, Hongjuan Ma ${ }^{1}$ and Guozhong $\mathrm{Wu}^{1 \text {,* }}$ \\ 1 Shanghai Institute of Applied Physics, Chinese Academy of Sciences, Shanghai 201800, China; \\ lirong@sinap.ac.cn (R.L.); liyuna@sinap.ac.cn (Y.L.); zhangmaojiang@sinap.ac.cn (M.Z.); \\ xingzhe@sinap.ac.cn (Z.X.); mahongjuan@sinap.ac.cn (H.M.) \\ 2 Department of Chemistry, College of Sciences, Shanghai University, Shanghai 200444, China \\ 3 University of Chinese Academy of Sciences, Beijing 100049, China \\ * Correspondence: wuguozhong@sinap.ac.cn; Tel.: +86-21-3919-4531
}

Academic Editors: Melissa A. Denecke and Laura Leay

Received: 24 April 2018; Accepted: 22 May 2018; Published: 23 May 2018

\begin{abstract}
This work provides a cost-effective approach for preparing functional polymeric fibers used for removing uranium $(\mathrm{U}(\mathrm{VI}))$ from carbonate solution containing NaF. Phosphate-based ultrahigh molecular weight polyethylene (UHMWPE-g- $\mathrm{PO}_{4}$ ) fibers were developed by grafting of glycidyl methacrylate, and ring-opening reaction using phosphoric acid. Uranium $(\mathrm{U}(\mathrm{VI}))$ adsorption capacity of UHMWPE-g- $\mathrm{PO}_{4}$ fibers was dependent on the density of phosphate groups $\left(\mathrm{D}_{\mathrm{PO}}, \mathrm{mmol} \cdot \mathrm{g}^{-1}\right)$. UHMWPE-g-PO $\mathrm{P}_{4}$ fibers with a $\mathrm{D}_{\mathrm{PO}}$ of $2.01 \mathrm{mmol} \cdot \mathrm{g}^{-1}$ removed $99.5 \%$ of $\mathrm{U}(\mathrm{VI})$ from a $\mathrm{Na}_{2} \mathrm{CO}_{3}$ solution without the presence of $\mathrm{NaF}$. In addition, when $\mathrm{NaF}$ concentration was $3 \mathrm{~g} \cdot \mathrm{L}^{-1}, 150$ times larger than that of $\mathrm{U}(\mathrm{VI})$, the $\mathrm{U}(\mathrm{VI})$ removal ratio was still able to reach $92 \%$. The adsorption process was proved to follow pseudo-second-order kinetics and Langmuir isotherm model. The experimental maximum $\mathrm{U}(\mathrm{VI})$ adsorption capacity $\left(\mathrm{Q}_{\max }\right)$ of $\mathrm{UHMWPE}-\mathrm{g}-\mathrm{PO}_{4}$ fibers reached $110.7 \mathrm{mg} \cdot \mathrm{g}^{-1}$, which is close to the calculated $\mathrm{Q}_{\max }\left(117.1 \mathrm{mg} \cdot \mathrm{g}^{-1}\right)$ by Langmuir equation. Compared to $\mathrm{F}^{-}, \mathrm{Cl}^{-}, \mathrm{NO}_{3}{ }^{-}$, and $\mathrm{SO}_{4}{ }^{2-}$ did not influence $\mathrm{U}(\mathrm{VI})$ removal ratio, but, $\mathrm{H}_{2} \mathrm{PO}_{4}{ }^{-}$and $\mathrm{CO}_{3}{ }^{2-}$ significantly reduced $\mathrm{U}(\mathrm{VI})$ removal ratio in the order of $\mathrm{F}^{-}>\mathrm{H}_{2} \mathrm{PO}_{4}{ }^{-}>\mathrm{CO}_{3}{ }^{2-}$. Cyclic $\mathrm{U}(\mathrm{VI})$ sorption-desorption tests suggested that UHMWPE-g-PO $\mathrm{P}_{4}$ fibers were reusable. These results support that UHMWPE-g-PO $\mathrm{P}_{4}$ fibers can efficiently remove $\mathrm{U}(\mathrm{VI})$ from carbonate solutions containing $\mathrm{NaF}$.
\end{abstract}

Keywords: ultrahigh molecular weight polyethylene fibers; radiation induced graft polymerization; glycidyl methacrylate; phosphate group; removal of uranium from carbonate solution

\section{Introduction}

During the process of uranium enrichment, the yellow cake is converted into uranium hexafluoride $\left(\mathrm{UF}_{6}\right)$ gas for uranium isotopic enrichment, accompanied by the generation of exhaust gas, which is treated with aqueous sodium carbonate $\left(\mathrm{Na}_{2} \mathrm{CO}_{3}\right)$ solution. Consequently, an alkaline uranium-rich effluent is generated, where uranium exists mainly as uranyl carbonate complexes, e.g., $\mathrm{UO}_{2}\left(\mathrm{CO}_{3}\right)_{2}{ }^{2-}$ and $\mathrm{UO}_{2}\left(\mathrm{CO}_{3}\right)_{3}{ }^{4-}[1,2]$. The efficient sequestration of uranium from its secondary sources and wastewater, to decrease the uranium concentration below the recommended value for discharge, is one of the biggest challenges of the uranium enrichment industry, and developing techniques to solve this problem has attracted great interest [3]. This is mainly driven by two factors: (1) reducing uranium pollution to protect the environment, ecosystem, and human health, and (2) recycling and saving uranium resources [4].

Several main methods for the recovery of uranium from aqueous solution have been investigated over the past decades, including solvent extraction, ion exchange, and adsorption. Solvent extraction, 
as a well-established method, is economically viable when the concentration of solute and the flow rate of wastewater are both high, and becomes uneconomic when the concentration of solute is lower than $0.5 \mathrm{~g} \cdot \mathrm{L}^{-1}$ [5]. Additionally, this method is to some degree not environment-friendly. As a well-known example of solvent extraction operation, the plutonium uranium recovery by extraction (PUREX) process, used for recovering uranium and plutonium, produces large amounts of aqueous and organic radioactive waste solutions [6]. For the ion-exchange technology, the volume of ion-exchange resin used is dependent on the concentration of solute. Thus, when the concentration of solute is high, a large size of equipment is necessary, which makes such a process economically unfeasible [5]. Research has therefore been mainly focused on developing functional solid sorbents with selectivity. Because adsorption techniques have significant merits, including good feasibility and practicality, and flexible design and operation, various kinds of sorbents have been fabricated for the extraction of uranium from water solutions, e.g., synthetic polymeric [7], biopolymeric [8], inorganic [9], mesoporous silica-based [10], porous carbon-based [11], metal-organic framework-based [12], and ionic liquids [13] adsorbents. Among these types of sorbents, the polymeric sorbents, especially polymeric fibers, have several advantages, such as light weight, simple process of fabrication into various shapes and lengths, facility of deployment, and ease of recyclability and reusability [14].

The amidoxime group has been proven to have a high affinity for uranium in aqueous solutions. Amidoxime-based polymeric fibers are extensively used for the capture of uranium from aqueous solution and seawater [15]. However, amidoxime-based sorbents suffer from one main shortcoming, i.e., relatively slow sorption kinetics, which has been attributed to a reaction-limited process [16]. Additionally, the acrylonitrile monomer used to prepare amidoxime-based sorbents is explosive and toxic. Adsorbents with phosphonic acid functionality are widely used for the extraction and the separation of lanthanides and actinides, since phosphonic acid groups can form stable complexes with them [17]. Research has been conducted on the recovery of uranium species from aqueous phases by sorbent-tethered phosphonic acid groups, e.g., phosphonic acid-based mesoporous silica [17,18] and poly(styrene-co-divinylbenzene) [19], vinylphosphonic acid grafted poly(vinyl alcohol) fibers [20], phosphate-based mesoporous carbon [21], and poly(ethylene glycol methacrylate phosphate) grafted polypropylene membrane [22]. However, it is difficult to find a technically and economically feasible sorbent, fabricated in a simple way using inexpensive precursors, that can be considered as a potential sorbent for recovering uranium from wastewater.

Herein, we developed a kind of phosphate-based ultrahigh molecular weight polyethylene (UHMWPE-g- $\mathrm{PO}_{4}$ ) fiber adsorbent by the radiation grafting of glycidyl methacrylate (GMA) and ring-opening reaction of epoxy groups with phosphoric acid $\left(\mathrm{H}_{3} \mathrm{PO}_{4}\right)$ (see Scheme 1). UHMWPE fiber was used as the substrate, owing to its property of high strength and excellent resistance to corrosion even after radiation grafting [23]. Moreover, the free radicals formed in the UHMWPE fiber have a long life span, which is beneficial for the grafting reaction [24]. In this work, the uranium (U(VI)) loading capacity and removal ratio of the UHMWPE-g- $\mathrm{PO}_{4}$ fiber sorbent were evaluated by adsorption experiments performed in solution, prepared with uranyl nitrate hexahydrate $\left(\mathrm{UO}_{2}\left(\mathrm{NO}_{3}\right)_{2} \cdot 6 \mathrm{H}_{2} \mathrm{O}\right)$, $\mathrm{Na}_{2} \mathrm{CO}_{3}$, sodium fluoride $(\mathrm{NaF})$, and deionized water. The molar ratio of $\mathrm{UO}_{2}\left(\mathrm{NO}_{3}\right)_{2} \cdot 6 \mathrm{H}_{2} \mathrm{O}$ to anhydrous $\mathrm{Na}_{2} \mathrm{CO}_{3}$ was 1:5 in all the $\mathrm{U}(\mathrm{VI})$ aqueous solutions. In previous works, anionic resins $[1,25]$ and ionic liquid [13] have been used to extract U(VI) from carbonate solution containing fluoride ions. To the best of our knowledge, this research is the first reported work on phosphate-based sorbents used for removal of U(VI) from carbonate solution containing fluoride ions. 


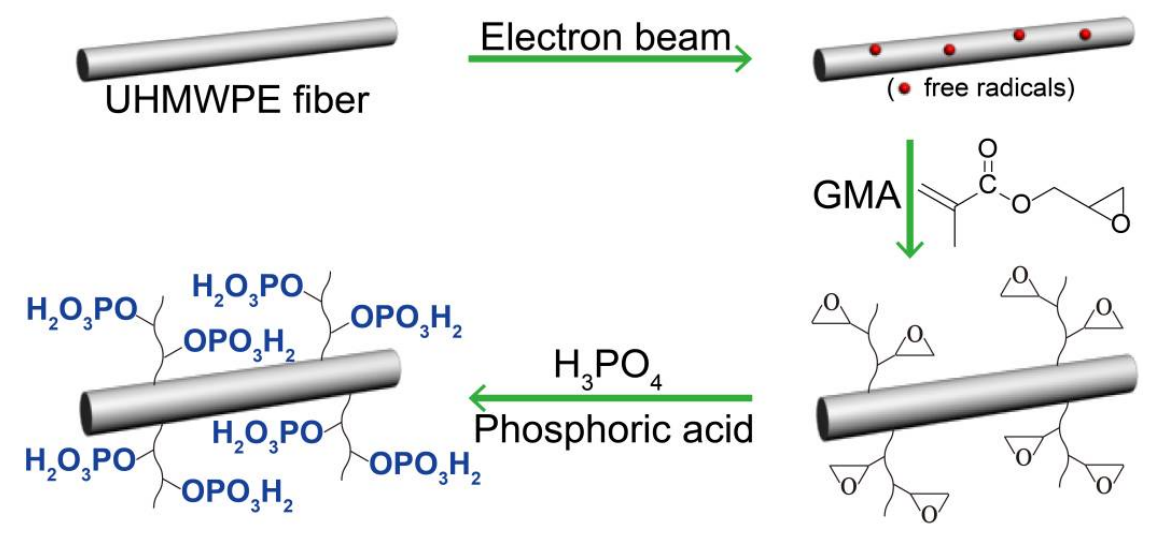

Scheme 1. The synthetic route for UHMWPE-g-PO fiber sorbent.

\section{Results}

\subsection{Radiation Grafting Kinetics of GMA}

The kinetics of graft polymerization of GMA onto the UHMWPE fibers was investigated to determine the optimum grafting parameters. Figure 1a shows the degree of grafting (DG) versus the absorbed dose. The DG initially enhances with an increase of absorbed dose from 50 to $150 \mathrm{kGy}$ attributable to the increasing absorbed dose raising the amount of free radicals [24]. However, the DG declines with a further increase of the absorbed dose from 150 to $250 \mathrm{kGy}$. This is mainly ascribed to radiation-induced degradation of the UHMWPE chains from the high absorbed dose in air [26]. Figure $1 \mathrm{~b}$ describes the relationship between DG and monomer concentration. As anticipated, the DG logically increases with the GMA concentration due to more available monomers taking part in the graft reaction. Figure $1 \mathrm{c}$ depicts the effect of reaction temperature on the DG. An increase in the temperature from 30 to $70{ }^{\circ} \mathrm{C}$ is accompanied by an increase in the DG. This is ascribed to the high temperature stimulating the diffusion of monomer into the grafting sites on fibers [27]. However, the DG reduces when the temperature is more than $70{ }^{\circ} \mathrm{C}$. This might be caused by GMA homopolymerization dominating at high temperature. Figure $1 \mathrm{~d}$ portrays the influence of reaction time on the DG. The DG increases for the first $2 \mathrm{~h}$, and then tends to level off. Consequently, the optimum grafting reaction conditions might be $150 \mathrm{kGy}, 65-70{ }^{\circ} \mathrm{C}$, and $2 \mathrm{~h}$, and the desired DG can be simply obtained by adjusting the monomer concentration.
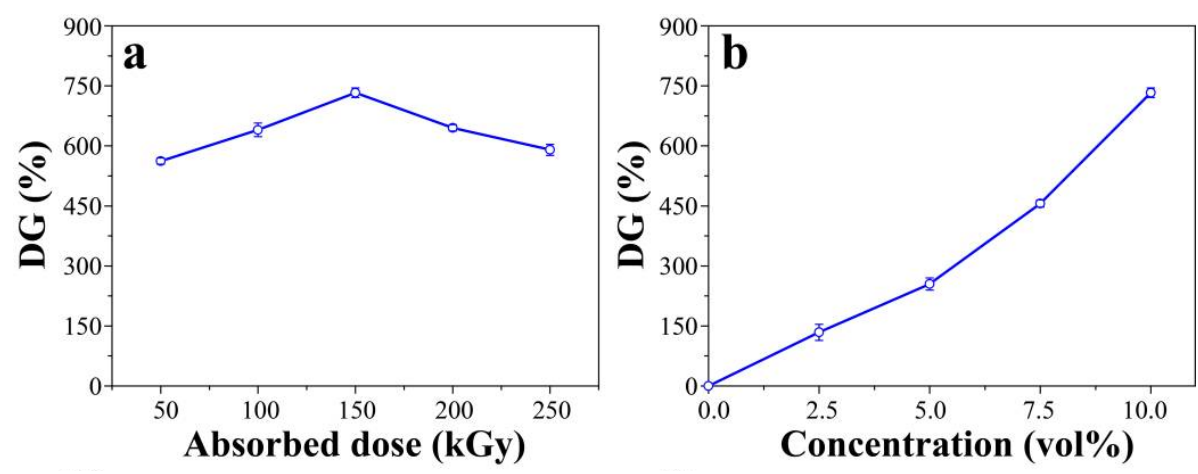

Figure 1. Cont. 

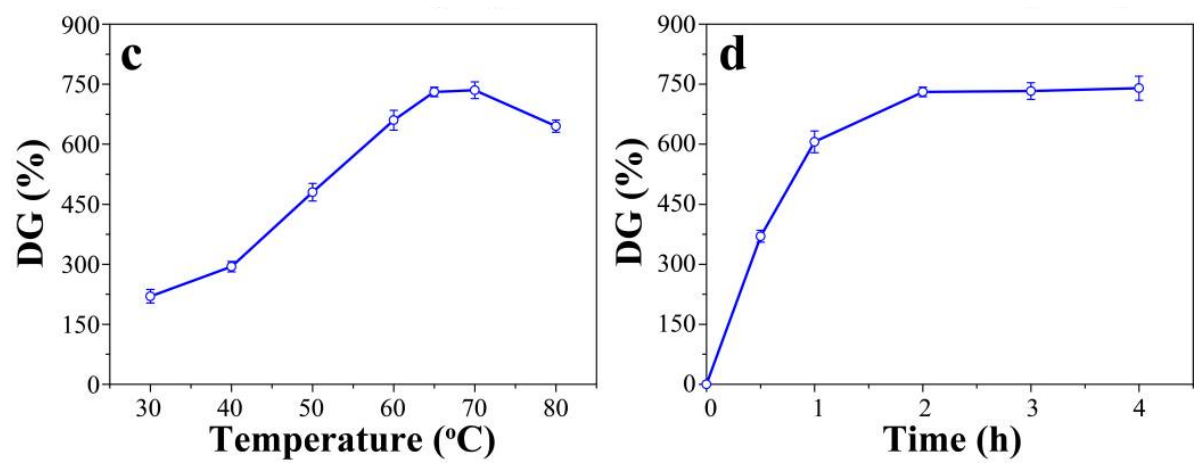

Figure 1. DG of UHMWPE fibers as a function of (a) absorbed dose (10 vol\%, $\left.65{ }^{\circ} \mathrm{C}, 2 \mathrm{~h}\right)$, (b) GMA concentration $\left(150 \mathrm{kGy}, 65^{\circ} \mathrm{C}, 2 \mathrm{~h}\right)$, (c) reaction temperature (150 kGy, $\left.10 \mathrm{vol} \%, 2 \mathrm{~h}\right)$, and (d) reaction time $\left(150 \mathrm{kGy}, 10 \mathrm{vol} \%, 65^{\circ} \mathrm{C}\right)$.

\subsection{Characterization of Modified UHMWPE Fibers}

Figure 2 portrays the attenuated total reflectance Fourier transform infrared (ATR-FTIR) spectroscopy of UHMWPE fibers. The original UHMWPE fiber has reflection bands at 2909, 2843, 1468, and $715 \mathrm{~cm}^{-1}$, which are due to the asymmetrical stretching, symmetrical stretching, bending, and rocking vibrations of methylene $\left(\mathrm{CH}_{2}\right)$, respectively. After grafting (trace b), the stretching vibrations of $\mathrm{CH}_{3}$ at $2918 \mathrm{~cm}^{-1}, \mathrm{C}=\mathrm{O}$ at $1720 \mathrm{~cm}^{-1}$, and $\mathrm{C}-\mathrm{O}$ (ring) at $905 \mathrm{~cm}^{-1}$ confirm the successful grafting of GMA onto UHMWPE fiber [28]. After phosphation (trace c), the absorption peak of $\mathrm{C}-\mathrm{O}$ (ring) disappears, and fresh peaks of $\mathrm{OH}$ and $\mathrm{P}=\mathrm{O}$ originate at $3100-3500$ and at $930-1025 \mathrm{~cm}^{-1}$, respectively, demonstrating the successful introduction of the phosphate group onto UHMWPE fiber [29].

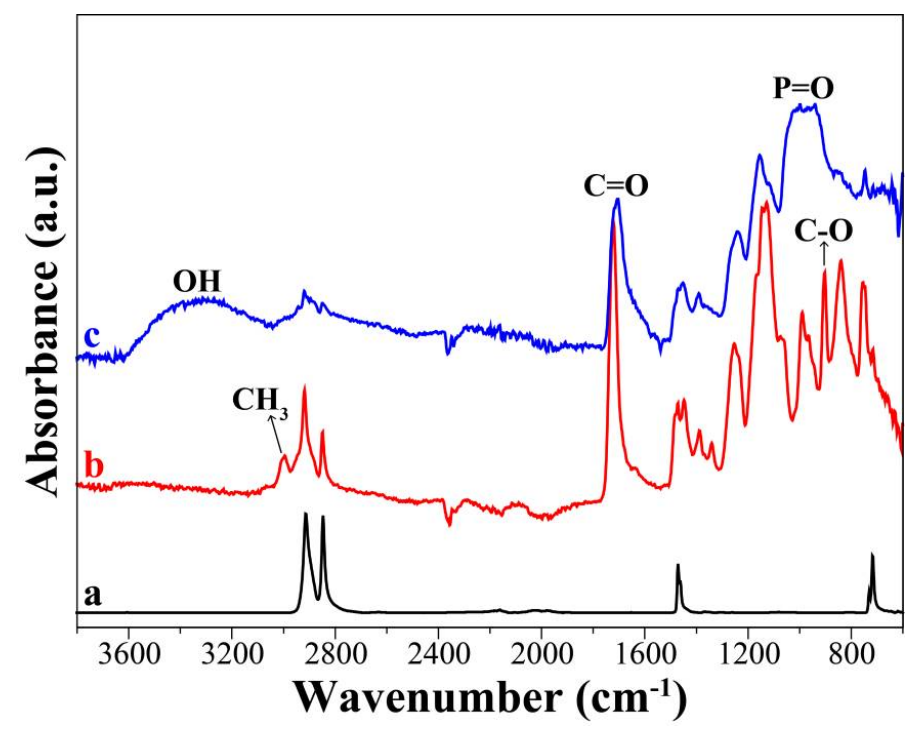

Figure 2. ATR-FTIR spectroscopy of (a) original UHMWPE, (b) UHMWPE-g-PGMA (DG = 540\%), and $(c)$ UHMWPE-PO $4\left(\mathrm{D}_{\mathrm{PO}}=1.93 \mathrm{mmol} \cdot \mathrm{g}^{-1}\right)$ fibers.

The chemical composition of the UHMWPE fibers was analyzed by X-ray photoelectron spectroscopy (XPS), as portrayed in Figure 3. The pristine UHMWPE fiber exhibits a strong C1s peak at $284.8 \mathrm{eV}(\mathrm{C}-\mathrm{C})$ and a weak $\mathrm{O} 1 \mathrm{~s}$ peak at $531.9 \mathrm{eV}$. The emergence of oxygen $(\mathrm{O}, 1.84 \%)$ element in the pristine UHMWPE fiber might be due to oxidation or contamination. After grafting of GMA, the $\mathrm{O}$ content evidently increases from $1.84 \%$ to $28.13 \%$, combined with a strong O1s peak at $532.8 \mathrm{eV}$. The $\mathrm{C}$ content decreases from $98.16 \%$ to $71.87 \%$, and the $\mathrm{C} 1$ s peak can be clearly decomposed into $\mathrm{C}-\mathrm{C}$ $(284.8 \mathrm{eV}), \mathrm{C}-\mathrm{O}(286.5 \mathrm{eV})$, and $\mathrm{O}=\mathrm{C}-\mathrm{O}(288.8 \mathrm{eV})$ peaks. For the $\mathrm{UHMWPE}^{-} \mathrm{-PO}{ }_{4}$ fiber, the $\mathrm{C}$ content 
decreases from $71.87 \%$ to $64.40 \%$, and the $\mathrm{O}$ content increases from $28.13 \%$ to $33.14 \%$, coupled with a much stronger O1s peak. Moreover, the appearance of a novel $\mathrm{P}_{2 p}$ peak at $134.0 \mathrm{eV}$ illustrates that phosphate groups are successfully introduced into the UHMWPE fibers.

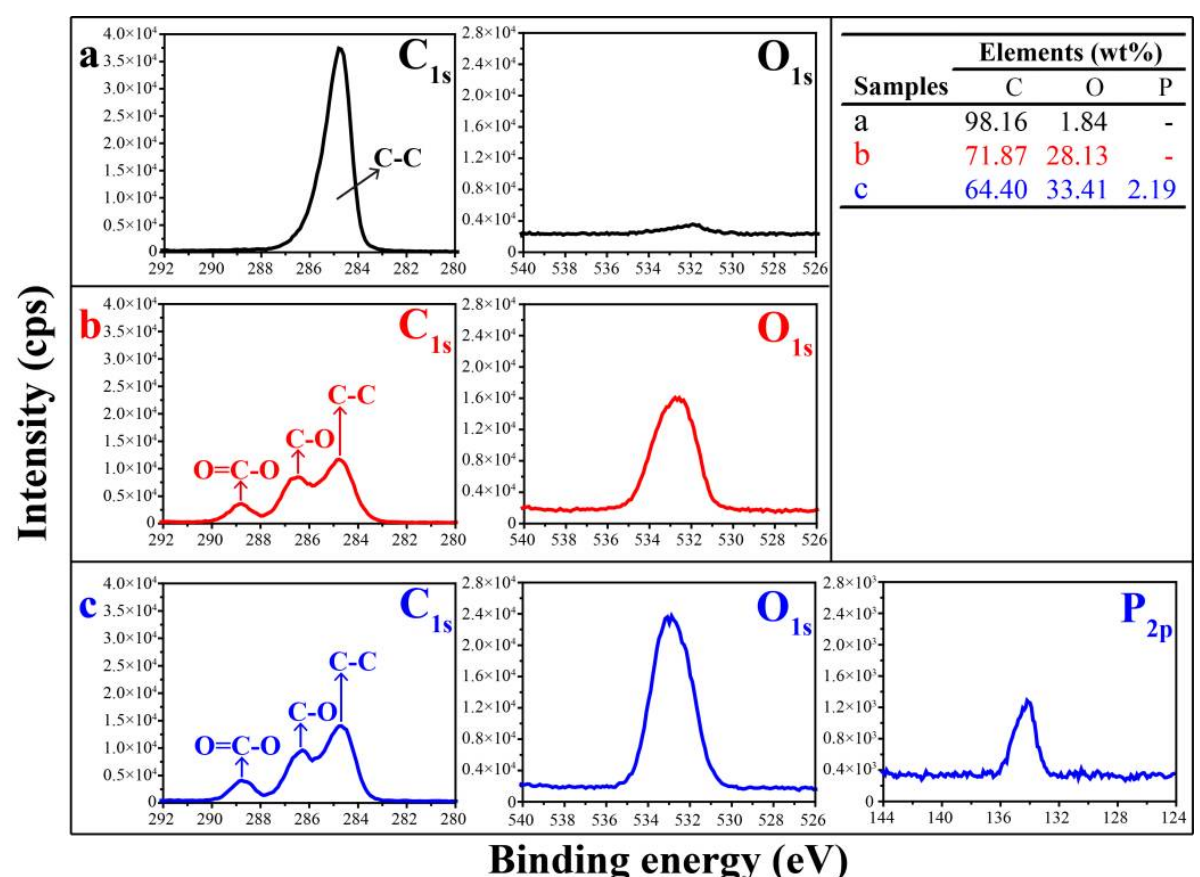

Figure 3. XPS spectra and the elements (inserted Table) of (a) pristine UHMWPE, (b) UHMWPEg-PGMA $(D G=540 \%)$, and $(c)$ UHMWPE-g- $\mathrm{PO}_{4}\left(\mathrm{D}_{\mathrm{PO}}=1.93 \mathrm{mmol} \cdot \mathrm{g}^{-1}\right)$ fibers.

\subsection{Uranium Adsorption}

Screening tests were conducted in U(VI) carbonate solutions with NaF to identify sorbents with high $\mathrm{U}(\mathrm{VI})$ adsorption capacities. As shown in Table 1, among the tested sorbents the sorbent with the highest $\mathrm{D}_{\mathrm{PO}}$ presents the highest $\mathrm{U}(\mathrm{VI})$ adsorption capacity.

Table 1. U(VI) adsorption capacities of UHMWPE-g-PO $\mathrm{PO}_{4}$ fibers with different $\mathrm{D}_{\mathrm{PO}}$ (initial U(VI) concentrations $\left(\mathrm{C}_{0}\right)$ : $20.0 \mathrm{mg} \cdot \mathrm{L}^{-1}$, sorbent: $0.2 \mathrm{~g}$, volume: $1 \mathrm{~L}, \mathrm{NaF}: 2.0 \mathrm{~g} \cdot \mathrm{L}^{-1}$, time: $24 \mathrm{~h}$, and temperature: $25^{\circ} \mathrm{C}$ ).

\begin{tabular}{cccc}
\hline \multirow{2}{*}{ Sorbents } & \multicolumn{2}{c}{ Sorbent Description } & Adsorption Capacity \\
\cline { 2 - 4 } & DG (\%) & D $_{\text {PO }}\left(\mathbf{m m o l} \cdot \mathbf{g}^{-\mathbf{1}}\right)$ & U(VI) $\left.\mathbf{~} \mathbf{m g} \cdot \mathbf{g}^{\mathbf{- 1}}\right)$ \\
\hline A & 186 & 1.55 & $38.9 \pm 1.1$ \\
B & 294 & 1.81 & $45.3 \pm 0.7$ \\
C & 540 & 1.93 & $56.4 \pm 1.3$ \\
D & 630 & 2.01 & $69.2 \pm 2.0$ \\
\hline
\end{tabular}

In order to compare the surface morphologies and elemental contents of the UHMWPE-g-PO fibers before and after $\mathrm{U}(\mathrm{VI})$ adsorption, a scanning electron microscope (SEM) equipped with energy dispersive X-ray (EDX) spectroscopy was used to observe the sample surface. Figure 4 displays the surface morphologies and EDX spectra of the non-adsorbed and U(VI)-loaded UHMWPE-g-PO fibers. Comparing Figure $4 \mathrm{a}$ with Figure $4 \mathrm{~b}$, it can be seen that the loaded U(VI) increases the mean diameter of the sorbent from $\sim 67.6 \mu \mathrm{m}$ to $\sim 89.6 \mu \mathrm{m}$. The EDX spectra and elemental contents are depicted in Figure $4 a^{\prime}, b^{\prime}$, and the inserted tables, respectively. In comparison with non-adsorbed fiber, the U(VI)-loaded fiber presents obvious $U(V I)$ absorption peaks in Figure $4 b^{\prime}$, and the content of U(VI) 
$(7.22 \mathrm{wt} \%)$ in the sorbent, to a certain extent, indicates the UHMWPE-g-PO ${ }_{4}$ sorbent can effectively capture uranium from carbonate solution with $\mathrm{NaF}$.

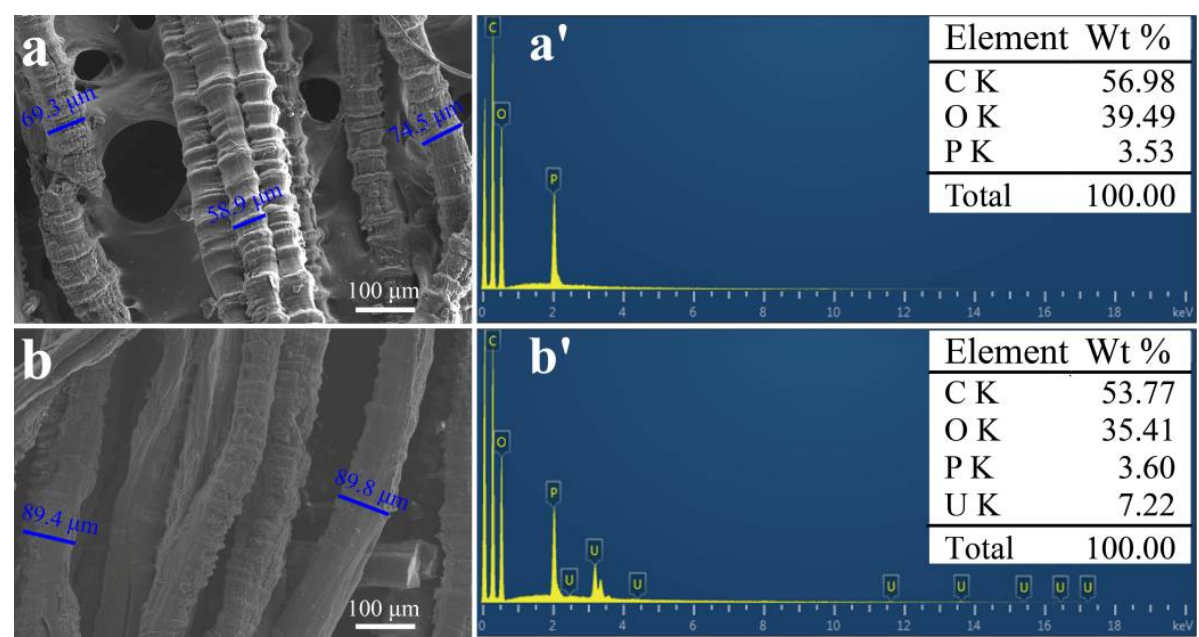

Figure 4. SEM pictures, EDX spectra of UHMWPE-g-PO fibers ( $D G=630 \% ; \mathrm{D}_{\mathrm{PO}}=2.01 \mathrm{mmol} \cdot \mathrm{g}^{-1}$ ) before $\left(\mathbf{a}, \mathbf{a}^{\prime}\right)$ and after $\left(\mathbf{b}, \mathbf{b}^{\prime}\right) \mathrm{U}(\mathrm{VI})$ adsorption $\left(\mathrm{C}_{0}: 20.0 \mathrm{mg} \cdot \mathrm{L}^{-1}\right.$, sorbent: $0.2 \mathrm{~g}$, volume: $1 \mathrm{~L}, \mathrm{NaF}$ : $2.0 \mathrm{~g} \cdot \mathrm{L}^{-1}$, time: $24 \mathrm{~h}$, and temperature: $25^{\circ} \mathrm{C}$ ).

The effect of sorption time on the U(VI) loading capacity and removal ratio of UHMWPE-g-PO fibers $\left(\mathrm{D}_{\mathrm{PO}}=2.01 \mathrm{mmol} \cdot \mathrm{g}^{-1}\right)$ was investigated using batch experiments at various time intervals from 0 to $144 \mathrm{~h}$, in order to determine the sorption kinetics. As shown in Figure 5a,b, both U(VI) adsorption capacity and removal ratio increase significantly with the sorption time during the first $24 \mathrm{~h}$, rise gradually up to $72 \mathrm{~h}$, and then level off to an equilibrium state. The U(VI) adsorption capacity and removal ratio reach $68.5 \mathrm{mg} \cdot \mathrm{g}^{-1}$ and $70 \%$ within $24 \mathrm{~h}$, and $91.6 \mathrm{mg} \cdot \mathrm{g}^{-1}$ and $93 \%$ at equilibrium, respectively.

Additionally, in order to understand the adsorption kinetics, pseudo-first-order and pseudo-second-order models were used to fit the experimental data. The two kinetic models were given in the linear form:

$$
\begin{aligned}
& \text { pseudo-first-order model: } \ln \left(\mathrm{Q}_{\mathrm{e}}-\mathrm{Q}_{\mathrm{t}}\right)=\ln \mathrm{Q}_{\mathrm{e}}-k_{1} \mathrm{t} \\
& \text { pseudo-second-order model: } \mathrm{t} / \mathrm{Q}_{\mathrm{t}}=1 /\left(k_{2} \cdot \mathrm{Q}_{\mathrm{e}}{ }^{2}\right)+\mathrm{t} / \mathrm{Q}_{\mathrm{e}}
\end{aligned}
$$

where $\mathrm{Q}_{\mathrm{e}}\left(\mathrm{mg} \cdot \mathrm{g}^{-1}\right)$ and $\mathrm{Q}_{\mathrm{t}}\left(\mathrm{mg} \cdot \mathrm{g}^{-1}\right)$ are the $\mathrm{U}(\mathrm{VI})$ loading amounts at equilibrium and at various contact time " $\mathrm{t}$ ", respectively. $k_{1}\left(\mathrm{~h}^{-1}\right)$ and $k_{2}\left(\mathrm{~g} \cdot \mathrm{mg}^{-1} \cdot \mathrm{h}^{-1}\right)$ are the pseudo-first-order and the pseudo-second-order rate constants of adsorption, respectively.

Two straight lines with correlation coefficients $\left(R^{2}\right)$ acquired by linear regression are shown in Figure 5c (pseudo-first-order) and Figure 5d (pseudo-second-order), respectively. The values of $\mathrm{Q}_{\mathrm{e}}$, $k_{1}, k_{2}$, and $\mathrm{R}^{2}$ are summarized in Table 2. The value of $\mathrm{R}^{2}(0.999)$ for the pseudo-second-order model is higher than that (0.978) of the pseudo-first-order model. Furthermore, as compared with that $\left(63.1 \mathrm{mg} \cdot \mathrm{g}^{-1}\right)$ of the pseudo-first-order model, the calculated $\mathrm{Q}_{\mathrm{e}}\left(95.2 \mathrm{mg} \cdot \mathrm{g}^{-1}\right)$ by the pseudo-second-order model is almost equal to that of the experimental $\mathrm{Q}_{\mathrm{e}}\left(91.6 \mathrm{mg} \cdot \mathrm{g}^{-1}\right)$. As a result, it can be concluded that the $\mathrm{U}(\mathrm{VI})$ adsorption kinetics on the UHMWPE-g-PO $\mathrm{PO}_{4}$ fiber follow a pseudo-second-order kinetic model. 

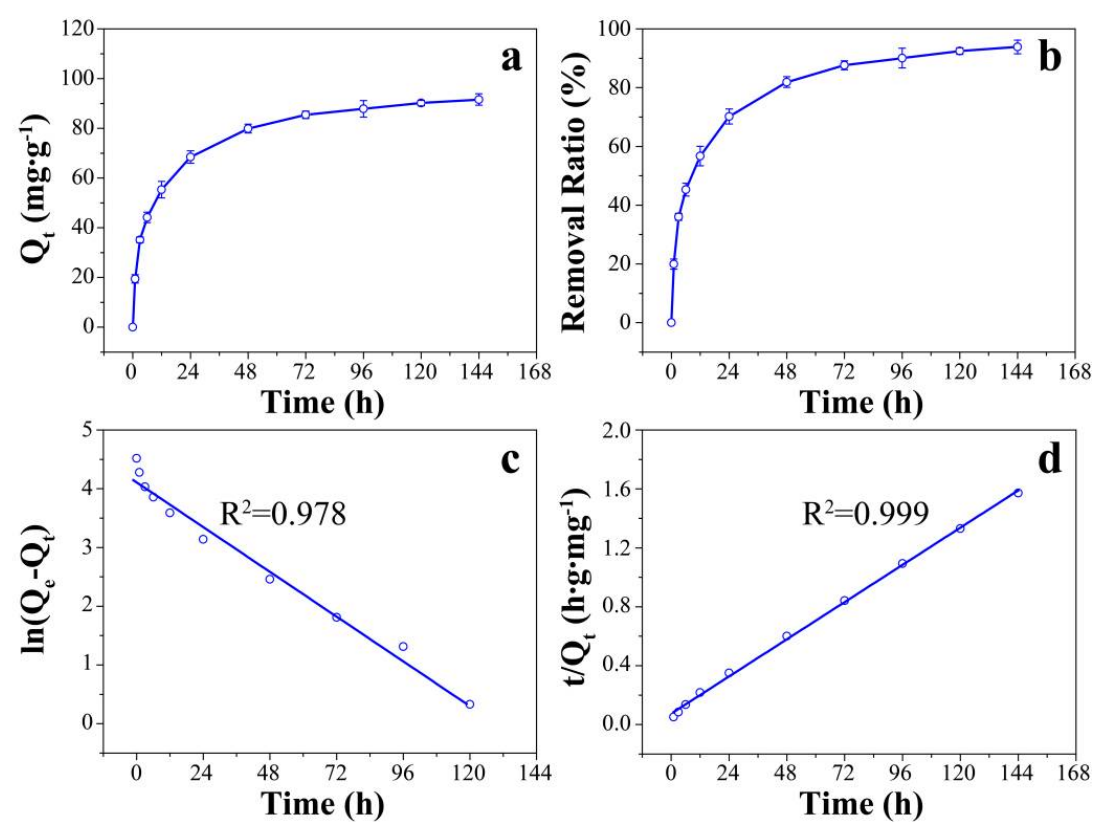

Figure 5. Influence of sorption time on the (a) U(VI) adsorption capacity and (b) removal ratio. U(VI) adsorption kinetic curves: (c) linearized pseudo-first-order and (d) pseudo-second-order kinetic models $\left(\mathrm{C}_{0}: 19.7 \mathrm{mg} \cdot \mathrm{L}^{-1}\right.$, sorbent: $0.2 \mathrm{~g}$, volume: $1 \mathrm{~L}, \mathrm{NaF}: 2.0 \mathrm{~g} \cdot \mathrm{L}^{-1}$, and temperature: $\left.25^{\circ} \mathrm{C}\right)$.

Table 2. Kinetic parameters for the sorption of U(VI) by UHMWPE-g-PO $\mathrm{PH}_{4}$ fiber.

\begin{tabular}{cccccc}
\hline \multicolumn{3}{c}{ Pseudo-First-Order } & \multicolumn{3}{c}{ Pseudo-Second-Order } \\
\hline $\mathrm{Q}_{\mathrm{e}}\left(\mathrm{mg} \cdot \mathrm{g}^{-1}\right)$ & $k_{1}\left(\mathrm{~h}^{-1}\right)$ & $\mathrm{R}^{2}$ & $\mathrm{Q}_{\mathrm{e}}\left(\mathrm{mg} \cdot \mathrm{g}^{-1}\right)$ & $k_{2}\left(\mathrm{~g} \cdot \mathrm{mg}^{-1} \cdot \mathrm{h}^{-1}\right)$ & $\mathrm{R}^{2}$ \\
63.1 & $3.17 \times 10^{-2}$ & 0.978 & 95.2 & $1.48 \times 10^{-3}$ & 0.999 \\
\hline
\end{tabular}

To assess the overall $\mathrm{U}(\mathrm{VI})$ adsorption capacity, an adsorption isotherm was collected by equilibrating the UHMWPE-g-PO $\mathrm{P}_{4}$ fibers with a wide range of initial U(VI) concentrations. Figure $6 \mathrm{a}, \mathrm{b}$ show that $\mathrm{Q}_{\mathrm{e}}$ increases sharply from $4.8 \mathrm{mg} \cdot \mathrm{g}^{-1}\left(\mathrm{C}_{0}: 1.1 \mathrm{mg} \cdot \mathrm{L}^{-1} ; \mathrm{U}(\mathrm{VI})\right.$ concentration at adsorption equilibrium $\left.\left(\mathrm{C}_{\mathrm{e}}\right): 0.2 \mathrm{mg} \cdot \mathrm{L}^{-1}\right)$ to $91.6 \mathrm{mg} \cdot \mathrm{g}^{-1}\left(\mathrm{C}_{0}: 19.7 \mathrm{mg} \cdot \mathrm{L}^{-1} ; \mathrm{C}_{\mathrm{e}}: 1.3 \mathrm{mg} \cdot \mathrm{L}^{-1}\right)$, and then increases slowly up to $110.7 \mathrm{mg} \cdot \mathrm{g}^{-1}\left(\mathrm{C}_{0}: 29.9 \mathrm{mg} \cdot \mathrm{L}^{-1} ; \mathrm{C}_{\mathrm{e}}, 7.8 \mathrm{mg} \cdot \mathrm{L}^{-1}\right)$.

The Langmuir and Freundlich models were used to analyze the equilibrium adsorption isotherms and investigate the adsorption mechanism of the adsorbent. The two equations were listed as:

$$
\begin{gathered}
\text { Langmuir equation: } \mathrm{C}_{\mathrm{e}} / \mathrm{Q}_{\mathrm{e}}=\mathrm{C}_{\mathrm{e}} / \mathrm{Q}_{\max }+1 /\left(\mathrm{Q}_{\max } \times K_{\mathrm{L}}\right) \\
\text { Freundlich equation: } \operatorname{lgQe}=\lg K_{\mathrm{F}}+(1 / n) \times \lg \mathrm{C}_{\mathrm{e}}
\end{gathered}
$$

where $C_{e}\left(m g \cdot \mathrm{L}^{-1}\right)$ is the $\mathrm{U}(\mathrm{VI})$ concentration at adsorption equilibrium, $\mathrm{Q}_{\mathrm{e}}\left(\mathrm{mg} \cdot \mathrm{g}^{-1}\right)$ is the $\mathrm{U}(\mathrm{VI})$ loading amount at equilibrium, $\mathrm{Q}_{\max }$ is the is the saturated Langmuir monolayer sorption capacity $\left(\mathrm{mg} \cdot \mathrm{g}^{-1}\right), K_{\mathrm{L}}\left(\mathrm{L} \cdot \mathrm{mg}^{-1}\right)$ is the Langmuir equilibrium constant related to the energy of adsorption and affinity of the adsorbent, and $K_{\mathrm{F}}\left(\mathrm{mg} \cdot \mathrm{g}^{-1}\right)$ and $n$ are the Freundlich constants representing sorption capacity and sorption intensity, respectively.

The linearized plots of the Langmuir and the Freundlich adsorption isotherms are given in Figure $6 c, d$. The values of $\mathrm{Q}_{\max }, K_{\mathrm{L}}, K_{\mathrm{F}}, n$, and $\mathrm{R}^{2}$ are shown in Table 3. In comparison with the $K_{\mathrm{F}}$ $\left(79.1 \mathrm{mg} \cdot \mathrm{g}^{-1}\right)$ computed by the Freundlich equation, the calculated $Q_{\max }\left(117.1 \mathrm{mg} \cdot \mathrm{g}^{-1}\right)$ using the Langmuir equation is very close to the experimental $Q_{\mathrm{e}}\left(110.7 \mathrm{mg} \cdot \mathrm{g}^{-1}\right)$ at the initial concentration of $29.9 \mathrm{mg} \cdot \mathrm{L}^{-1}$. Additionally, the correlation coefficient $\mathrm{R}^{2}$ (0.999) of the Langmuir model is higher than that (0.776) of the Freundlich model. Thus, we can conclude that the adsorption experimental results for the UHMWPE-g-PO ${ }_{4}$ fibers are in good agreement with the Langmuir model. 

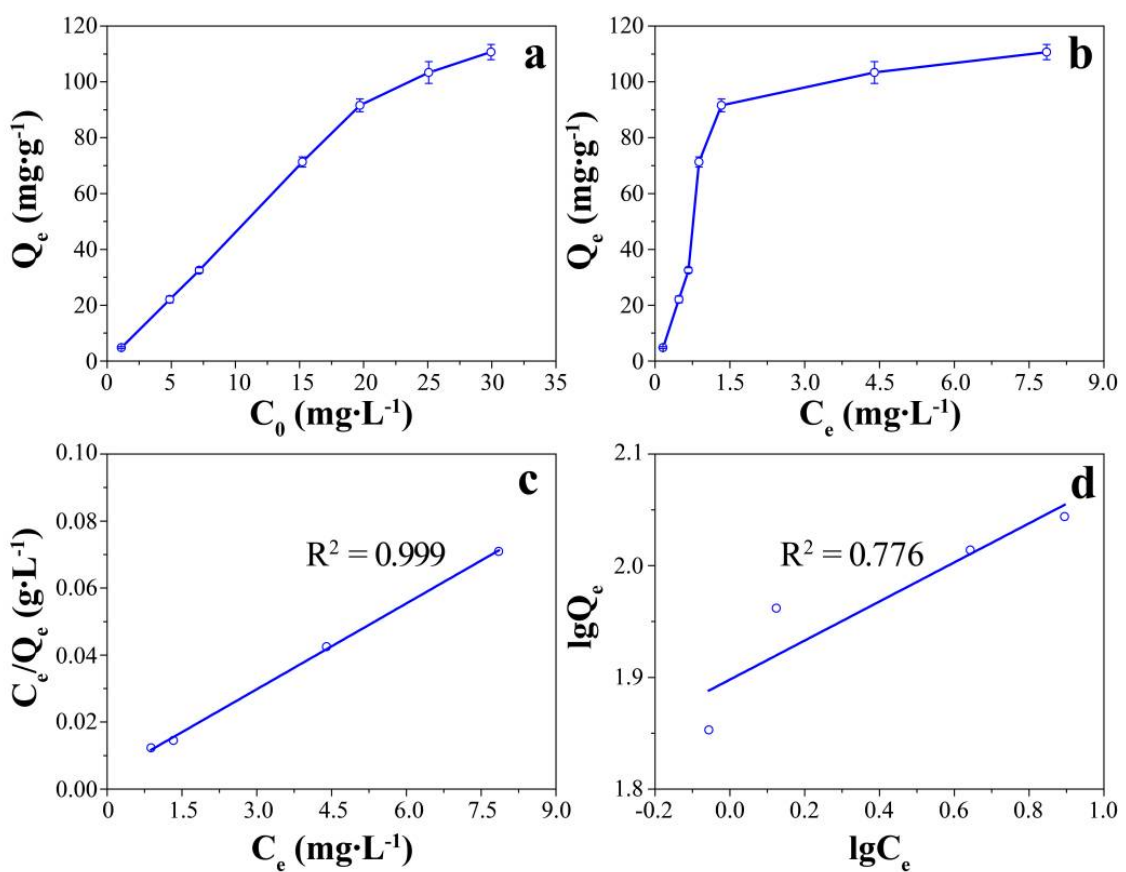

Figure 6. (a) Relationship between the $\mathrm{Q}_{\mathrm{e}}$ and the initial $\mathrm{U}(\mathrm{VI})$ concentration, (b) U(VI) adsorption isotherm for UHMWPE-g-PO $\mathrm{PO}_{4}$ fibers, (c) linearized Langmuir, and (d) Freundlich adsorption isotherms by fitting the experimental data (sorbent: $0.2 \mathrm{~g}$, volume: $1 \mathrm{~L}$, time: $144 \mathrm{~h}$, temperature: $25^{\circ} \mathrm{C}$, and $\mathrm{NaF}$ : $\left.2 \mathrm{~g} \cdot \mathrm{L}^{-1}\right)$.

Table 3. Parameters calculated from Langmuir and Freundlich models for the capture of U(VI) by UHMWPE-g- $\mathrm{PO}_{4}$ fiber.

\begin{tabular}{cccccc}
\hline \multicolumn{3}{c}{ Langmuir Model } & \multicolumn{3}{c}{ Freundlich Model } \\
\hline $\mathrm{Q}_{\max }\left(\mathrm{mg} \cdot \mathrm{g}^{-1}\right)$ & $\mathrm{K}_{\mathrm{L}}\left(\mathrm{L} \cdot \mathrm{mg}^{-1}\right)$ & $\mathrm{R}^{2}$ & $K_{\mathrm{F}}\left(\mathrm{mg} \cdot \mathrm{g}^{-1}\right)$ & $n$ & $\mathrm{R}^{2}$ \\
117.1 & 2.0 & 0.999 & 79.1 & 5.7 & 0.776 \\
\hline
\end{tabular}

In the alkaline wastewater that is produced in a uranium enrichment plant, there is a lot of fluoride. Hence, the effect of $\mathrm{F}^{-}$ions on the $\mathrm{U}(\mathrm{VI})$ removal ratio was investigated in this work. The influences of other competitive anions, including chloride $\left(\mathrm{Cl}^{-}\right)$, nitrate $\left(\mathrm{NO}_{3}{ }^{-}\right)$, sulfate $\left(\mathrm{SO}_{4}{ }^{2-}\right)$, dihydrogen phosphate $\left(\mathrm{H}_{2} \mathrm{PO}_{4}{ }^{-}\right)$, and $\mathrm{CO}_{3}{ }^{2-}$ on the $\mathrm{U}(\mathrm{VI})$ removal ratio were explored as well. Figure 7 shows the relationships between the concentrations of various salts and the U(VI) removal ratio of UHMWPE-g- $\mathrm{PO}_{4}$ fibers. It should be mentioned here that the U(VI) removal ratio is $\sim 99.5 \%$ when no other anion is dissolved in the solution, which is used as the control. Figure 7a-c illustrate that the U(VI) removal ratios are almost unchanged with increasing concentrations of sodium chloride $(\mathrm{NaCl})$, sodium nitrate $\left(\mathrm{NaNO}_{3}\right)$, and sodium sulfate $\left(\mathrm{Na}_{2} \mathrm{SO}_{4}\right)$. This means that $\mathrm{Cl}^{-}, \mathrm{NO}_{3}{ }^{-}$, and $\mathrm{SO}_{4}{ }^{2-}$ do not exhibit competitive effects during the process of $\mathrm{U}(\mathrm{VI})$ adsorption. Figure $7 \mathrm{~d}$ portrays the effect of $\mathrm{NaF}$ concentration on the $\mathrm{U}(\mathrm{VI})$ removal ratio. When the NaF concentration is less than $3 \mathrm{~g} \cdot \mathrm{L}^{-1}$, the removal ratio is higher than $92 \%$. It should be emphasized that this NaF concentration $\left(3 \mathrm{~g} \cdot \mathrm{L}^{-1}\right)$ is 150 times higher than that $\left(\sim 20 \mathrm{mg} \cdot \mathrm{L}^{-1}\right)$ of $\mathrm{U}(\mathrm{VI})$ in the solution. This indicates that the UHMWPE-g- $\mathrm{PO}_{4}$ fiber sorbent has a high adsorption efficiency for U(VI) at a relatively low NaF concentration. However, with a further increase of NaF concentration from 6 to $40 \mathrm{~g} \cdot \mathrm{L}^{-1}$, the U(VI) removal ratio declines significantly from $73 \%$ to $10 \%$. This can be attributed to competitive coordination of U(VI) between phosphonyl oxygen and $\mathrm{F}^{-}$. The increasing concentration of $\mathrm{NaF}$ enhances the interaction between $\mathrm{F}^{-}$and $\mathrm{U}(\mathrm{VI})$, thereby decreasing the interaction between phosphonyl oxygen and $\mathrm{U}(\mathrm{VI})$, and thus reducing the U(VI) removal ratio [30]. Figure 7e describes the U(VI) removal 
ratio as a function of sodium dihydrogen phosphate $\left(\mathrm{NaH}_{2} \mathrm{PO}_{4}\right)$ concentration. The U(VI) removal ratio decreases with an increasing concentration of $\mathrm{NaH}_{2} \mathrm{PO}_{4}$. It can be ascribed to competitive coordination of $\mathrm{U}(\mathrm{VI})$ with phosphonyl oxygen from $\mathrm{NaH}_{2} \mathrm{PO}_{4}$. Figure $7 \mathrm{f}$ portrays the influence of $\mathrm{Na}_{2} \mathrm{CO}_{3}$ concentration on the $\mathrm{U}(\mathrm{VI})$ removal ratio. The $\mathrm{U}(\mathrm{VI})$ removal ratio is zero within $\mathrm{the}_{2} \mathrm{CO}_{3}$ concentration range of $1-20 \mathrm{~g} \cdot \mathrm{L}^{-1}$. This is due to strong coordination between $\mathrm{CO}_{3}{ }^{2-}$ and $\mathrm{U}(\mathrm{VI})$, which significantly inhibits the coordination between U(VI) and phosphonyl oxygen [31].
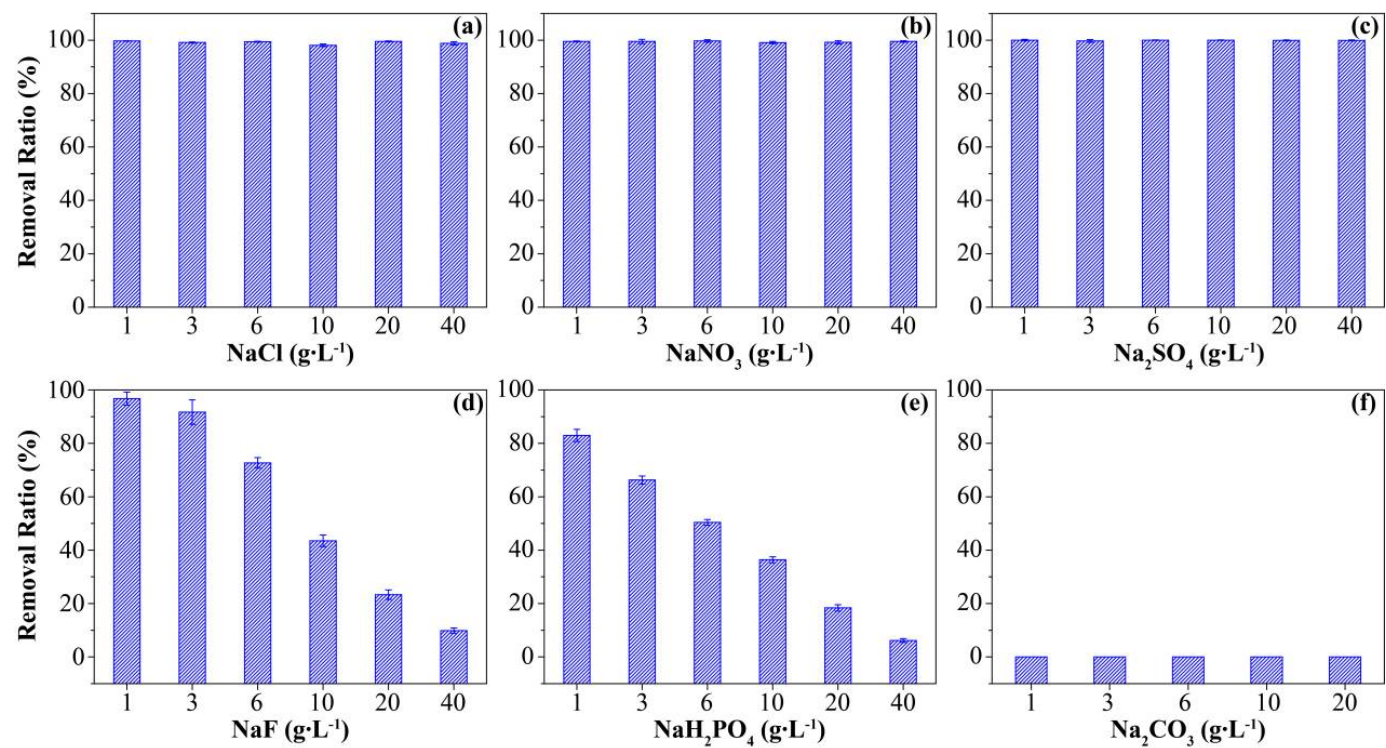

Figure 7. $\mathrm{U}(\mathrm{VI})$ removal ratio versus the concentrations of (a) $\mathrm{NaCl},(\mathbf{b}) \mathrm{NaNO}_{3}$, (c) $\mathrm{Na}_{2} \mathrm{SO}_{4}$, (d) $\mathrm{NaF},(\mathbf{e})$ $\mathrm{NaH}_{2} \mathrm{PO}_{4}$, and (f) $\mathrm{Na}_{2} \mathrm{CO}_{3}\left(\mathrm{C}_{0}: 19.5 \mathrm{mg} \cdot \mathrm{L}^{-1}\right.$, sorbent: $0.2 \mathrm{~g}$, volume: $1 \mathrm{~L}$, time: $144 \mathrm{~h}$, and temperature: $\left.25^{\circ} \mathrm{C}\right)$.

From the point of view of economy, it is necessary to investigate the effect of sorbent dosage on the $\mathrm{U}(\mathrm{VI})$ removal ratio with a certain initial concentration. The influence of sorbent dosage was explored with the sorbent dosage ranging from 0.1 to $1.0 \mathrm{~g} \cdot \mathrm{L}^{-1}$. As shown in Figure 8 , the U(VI) removal ratio shows a rapid increase as the sorbent dosage is raised from 0.1 to $0.3 \mathrm{~g} \cdot \mathrm{L}^{-1}$, owing to the higher amount of sorbent providing more available adsorption sites for capturing U(VI). At a sorbent dosage of $0.4 \mathrm{~g} \cdot \mathrm{L}^{-1}$ or higher, the $\mathrm{U}(\mathrm{VI})$ removal ratio is invariable at $96.9 \%$. This implies that an equilibrium has been achieved between the fibrous sorbent and the solution [32].

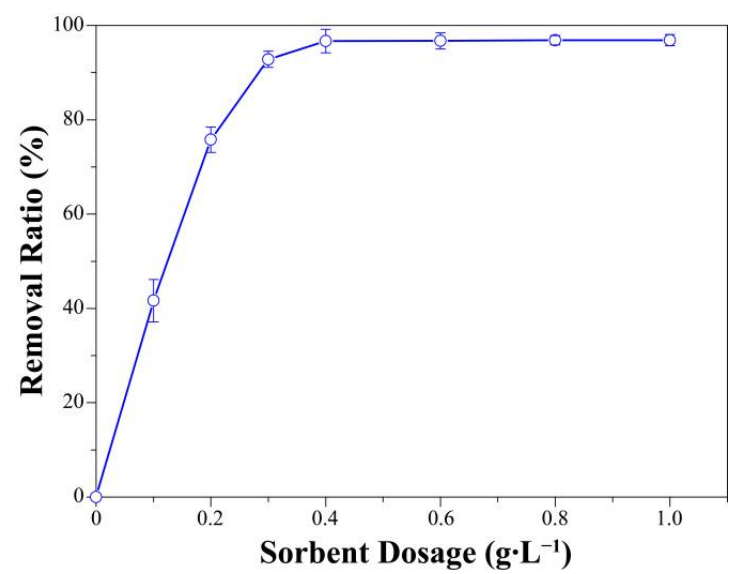

Figure 8. U(VI) removal ratio versus sorbent dosage $\left(\mathrm{C}_{0}: 29.8 \mathrm{mg} \cdot \mathrm{L}^{-1}, \mathrm{NaF}: 2 \mathrm{~g} \cdot \mathrm{L}^{-1}\right.$, volume: $1 \mathrm{~L}$, time: $144 \mathrm{~h}$, and temperature: $\left.25^{\circ} \mathrm{C}\right)$. 
Desorption of U(VI) from the UHMWPE-g-PO $\mathrm{PO}_{4}$ fibers can provide for better utilization of the fibers during the repeated recovery of $\mathrm{U}(\mathrm{VI})$, and reduce the cost of the adsorption process. $\mathrm{Na}_{2} \mathrm{CO}_{3}$ solution has been proved to be a good desorbent, with minimal effects on sorbent. Consequently, the $\mathrm{Na}_{2} \mathrm{CO}_{3}$ solution was used to desorb the loaded $\mathrm{U}(\mathrm{VI})$, and the desorbed sorbent was further used for up to four cycles of repetitive sorption-desorption under identical experimental conditions. As depicted in Figure 9, 15\% reduction in the removal ratio occurs after each consecutive run over the four cycles, thus about a 50\% removal ratio was achieved in the fourth cycle. These results show the potential reusability of UHMWPE-g- $\mathrm{PO}_{4}$ fibers for recovering $\mathrm{U}(\mathrm{VI})$ from carbonate solution containing $\mathrm{F}^{-}$ions.

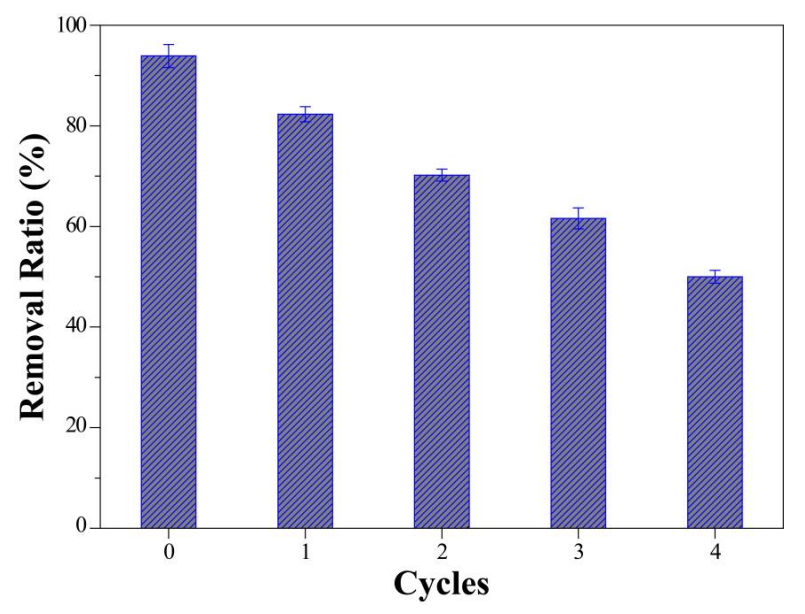

Figure 9. U(VI) removal ratio versus cycles $\left(\mathrm{C}_{0}: 19.7 \mathrm{mg} \cdot \mathrm{L}^{-1}, \mathrm{NaF}: 2 \mathrm{~g} \cdot \mathrm{L}^{-1}\right.$, sorbent: $0.2 \mathrm{~g}$, volume: $1 \mathrm{~L}$, time: $144 \mathrm{~h}$, and temperature: $25^{\circ} \mathrm{C}$ ).

\section{Discussion}

Radiation-induced graft polymerization of vinyl monomers onto polymers has received increasing attention due to its advantages of simplicity and facility to develop alternative functional polymeric materials [33]. In this work, EB irradiation was selected, owing to its high absorbed dose rate and short processing time, and was easy for pilot-scale production of functional polymers [34]. The investigation on the effects of absorbed dose, monomer concentration, temperature, and reaction time on the DG of GMA was carried out in order to achieve optimum grafting reaction parameters. Different DG can be easily obtained through adjustment of the above parameters. The characterizations via ATR-FTIR and XPS confirmed the successful graft polymerization of GMA and the introduction of phosphate group onto UHMWPE fibers (Figures 2 and 3).

Screening U(VI) adsorption test showed that the U(VI) adsorption capacity of UHMWPE-g-PO fiber had a positive correlation with the $\mathrm{D}_{\mathrm{PO}}$ (Table 1), illustrating that the $\mathrm{D}_{\mathrm{PO}}$ was a significant factor for extracting uranium [17]. However, a high DG will make the fiber sorbent more brittle, hereby decreasing its mechanical properties [35]. For this reason, fiber with a DG higher than $700 \%$ was not used in this work, and the UHMWPE-g-PO ${ }_{4}$ fiber with a DG of $630 \%\left(\mathrm{D}_{\mathrm{PO}}: 2.01 \mathrm{mmol} \cdot \mathrm{g}^{-1}\right)$ was selected for the adsorption studies. Batch adsorption experiments showed that the $\mathrm{U}(\mathrm{VI})$ adsorption by UHMWPE-g-PO $\mathrm{P}_{4}$ fiber followed the pseudo-second-order kinetic model and Langmuir isotherm model (Figures 5 and 6). This indicates that the $\mathrm{U}(\mathrm{VI})$ adsorption process is a chemisorption process, which is thought to be the monodentate coordination of phosphonyl oxygen and $\mathrm{UO}_{2}{ }^{2+}[36]$, and the uptake of $\mathrm{U}(\mathrm{VI})$ occurs on a homogeneous surface by monolayer adsorption. This result was well consistent with those of phosphate-based mesoporous carbon [21], polyethylene fiber [37], and mesoporous silica [38]. The U(VI) adsorption capacity of UHMWPE-g-PO $\mathrm{PO}_{4}$ fiber $\left(\mathrm{D}_{\mathrm{PO}}: 2.01 \mathrm{mmol} \cdot \mathrm{g}^{-1}\right)$ reached $110.7 \mathrm{mg} \cdot \mathrm{g}^{-1}$ in carbonate solution containing $\mathrm{F}^{-}$ions, indicating its potential application for the efficient removal of $\mathrm{U}(\mathrm{VI})$ from alkaline rich effluent or the other contaminated aqueous medium. 
For the UHMWPE-g-PO ${ }_{4}$ fiber sorbent, the U(VI) removal ratio was not affected in the presence of $\mathrm{Cl}^{-}, \mathrm{NO}_{3}{ }^{-}$, and $\mathrm{SO}_{4}{ }^{2-}$, but significantly reduced with the increasing concentrations of $\mathrm{F}^{-}, \mathrm{H}_{2} \mathrm{PO}_{4}{ }^{-}$, and $\mathrm{CO}_{3}{ }^{2-}$. This might be attributable to that $\mathrm{F}^{-}, \mathrm{H}_{2} \mathrm{PO}_{4}{ }^{-}$, and $\mathrm{CO}_{3}{ }^{2-}$, which have much stronger coordination ability to $\mathrm{U}(\mathrm{VI})$ than that of $\mathrm{Cl}^{-}, \mathrm{NO}_{3}{ }^{-}$, and $\mathrm{SO}_{4}{ }^{2-}$. Additionally, it can be clearly seen from Figure 7 that (1) the impact of coexisting anions on the $\mathrm{U}(\mathrm{VI})$ removal ratio increases in the order of $\mathrm{F}^{-}<\mathrm{H}_{2} \mathrm{PO}_{4}{ }^{-}<\mathrm{CO}_{3}{ }^{2-}$, (2) $\mathrm{H}_{2} \mathrm{PO}_{4}{ }^{-}$is more prone to coordinate with $\mathrm{U}(\mathrm{VI})$ than $\mathrm{F}^{-}$so that UHMWPE-g- $\mathrm{PO}_{4}$ fiber is able to extract $\mathrm{U}(\mathrm{VI})$ from carbonate solution containing $\mathrm{F}^{-}$, and (3) $\mathrm{Na}_{2} \mathrm{CO}_{3}$ aqueous solution is an efficient eluent for the regeneration of UHMWPE-g- $\mathrm{PO}_{4}$ fiber for the recycling.

Table 4 shows the $\mathrm{U}(\mathrm{VI})$ adsorption capacity of UHMWPE-g- $\mathrm{PO}_{4}$ fibers, compared with the other kinds of phosphate-based or phosphonic acid-based adsorbents. The UHMWPE-g-PO ${ }_{4}$ fibers present a good adsorption capacity for extracting $\mathrm{U}(\mathrm{VI})$ from a carbonate solution containing $\mathrm{F}^{-}$ions, and can be comparable with those adsorbents with phosphate or phosphonic acid groups $[17,20,21,39]$, extracting $\mathrm{U}(\mathrm{VI})$ from aqueous or carbonate solutions without the presence of $\mathrm{F}^{-}$ions. However, the U(VI) adsorption capacity of UHMWPE-g- $\mathrm{PO}_{4}$ fibers is lower than those of phosphate-based polyethylene fiber [37] and mesoporous silica [38], and phosphonic acid-based mesoporous silica [40]. This can be mainly attributed to the low initial $\mathrm{U}(\mathrm{VI})$ concentration and the existence of $\mathrm{F}^{-}$ions in the carbonate solution. Herein, it should be noted that the fiber sorbents are extremely facile to be placed in $\mathrm{U}(\mathrm{VI})$ solution, recovered from solution, and regenerated by eluent, as compared to phosphate-based mesoporous silica and carbon. Furthermore, in comparison with solvent extraction and ion-exchange resin, the UHMWPE-g-PO $\mathrm{P}_{4}$ fiber sorbent can be directly immersed into the $\mathrm{U}(\mathrm{VI})$ solution without the need for auxiliary equipment and the generation of extra waster solution. In addition, the amount of fiber sorbent used can be simply adjusted according to the U(VI) concentration.

Table 4. U(VI) adsorption performance of UHMWPE-g-PO $\mathrm{PO}_{4}$ fibers compared with other adsorbents containing phosphate or phosphonic acid groups.

\begin{tabular}{|c|c|c|c|c|c|c|}
\hline Sorbents & $\mathrm{C}_{0}\left(\mathrm{mg} \cdot \mathrm{L}^{-1}\right)$ & $\mathrm{pH}$ & $\mathrm{CO}_{3}{ }^{2-}$ & $\mathbf{F}^{-}$ & $\underset{\left(\mathrm{mg} \cdot \mathrm{g}^{-1}\right)}{\mathrm{Q}_{\max }}$ & Reference \\
\hline phosphonic acid-based mesoporous silica & 8 & 8.3 & with & without & 54.5 & [17] \\
\hline vinylphosphonic acid grafted poly(vinyl alcohol) fiber & 98.6 & 8.0 & without & without & 30.0 & [20] \\
\hline Phosphate-based mesoporous carbon & 50 & 8.0 & without & without & 70.0 & [21] \\
\hline phosphate-based polyethylene fibers & 50 & 8.2 & without & without & 151.0 & [37] \\
\hline phosphate-based mesoporous silica & 160 & 6.9 & without & without & 303.0 & [38] \\
\hline phosphate-based UHMWPE fiber & 20 & 9.6 & with & with & 110.7 & this work \\
\hline
\end{tabular}

Although the selectivity of the UHMWPE-g- $\mathrm{PO}_{4}$ fiber for $\mathrm{U}(\mathrm{VI})$ is proved to be much higher than for $\mathrm{F}^{-}$in this work, the industrial alkaline effluent usually contains high concentrations of $\mathrm{F}^{-}$ $\left(\sim 100 \mathrm{~g} \cdot \mathrm{L}^{-1}\right)$ [1], which could drastically reduce the U(VI) adsorption capacity of $\mathrm{UHMWPE} \mathrm{g}-\mathrm{PO}_{4}$ fiber sorbent. Consequently, future works should be focused on the development of functional polymeric fiber sorbent with enhanced selectivity toward $\mathrm{U}(\mathrm{VI})$ in the effluent containing high concentration of $\mathrm{F}^{-}$.

\section{Materials and Methods}

\subsection{Materials}

UHMWPE fiber (linear density: 3.6 Denier; diameter: $15 \mu \mathrm{m}$ ) was obtained from Beijing Tongyizhong Specialty Fiber Technology \& Development Co., Ltd. GMA (AR), $\mathrm{H}_{3} \mathrm{PO}_{4}(\mathrm{GR}, \sim 85 \mathrm{wt} \%)$, methanol $\left(\mathrm{CH}_{3} \mathrm{OH}, \mathrm{AR}\right)$, dichloromethane $\left(\mathrm{CH}_{2} \mathrm{Cl}_{2}, \mathrm{AR}\right), \mathrm{UO}_{2}\left(\mathrm{NO}_{3}\right)_{2} \cdot 6 \mathrm{H}_{2} \mathrm{O}$ (B\&A Quality), anhydrous $\mathrm{Na}_{2} \mathrm{CO}_{3}(\mathrm{AR})$, anhydrous $\mathrm{NaF}(\mathrm{AR})$, anhydrous $\mathrm{NaCl}$ (AR), anhydrous $\mathrm{NaNO}_{3}$ (AR), anhydrous $\mathrm{Na}_{2} \mathrm{SO}_{4}(\mathrm{AR})$, and $\mathrm{NaH}_{2} \mathrm{PO}_{4}(\mathrm{AR})$ were bought from Sinopharm Chemical Reagent Co., Ltd. (Shanghai, China) All the reagents were directly used without further purification. 


\subsection{Preparation of UHMWPE-g-PO ${ }_{4}$ Fiber Adsorbent}

UHMWPE fibers were irradiated in air with an electron beam using $1.5 \mathrm{MeV}$ electrons from a Dynamitron electron beam accelerator (Shanghai Institute of Applied Physics, Chinese Academy of Sciences). The irradiated fibers were immediately immersed in a $100 \mathrm{~mL}$ flask containing grafting solutions consisting of GMA in $\mathrm{H}_{2} \mathrm{O} / \mathrm{CH}_{3} \mathrm{OH}(50 / 50 \mathrm{vol} \%)$. The flask was then placed in a water bath for grafting under a nitrogen atmosphere. Subsequently, the grafted UHMWPE (UHMWPE-g-PGMA) fibers were thoroughly washed with $\mathrm{CH}_{2} \mathrm{Cl}_{2}$ and water to remove unreacted monomers and homopolymers, and dried at $60^{\circ} \mathrm{C}$ overnight under a vacuum. The DG was determined by Equation (5):

$$
\operatorname{DG}(\%)=\left(\mathrm{W}_{\mathrm{g}}-\mathrm{W}_{\mathrm{o}}\right) \times 100 / \mathrm{W}_{\mathrm{o}}
$$

where $\mathrm{W}_{\mathrm{o}}$ and $\mathrm{W}_{\mathrm{g}}$ are the weights of the original UHMWPE and UHMWPE-g-PGMA fibers.

The phosphate group was introduced in the fibers through the ring-opening reaction of epoxy groups with $\mathrm{H}_{3} \mathrm{PO}_{4} .1 \mathrm{~g}$ of UHMWPE-g-PGMA fiber was immersed in $100 \mathrm{~mL}$ of $\mathrm{H}_{3} \mathrm{PO}_{4}(\sim 85 \mathrm{wt} \%)$ at $80^{\circ} \mathrm{C}$ for $36 \mathrm{~h}$, in order to drive the reaction to completion [41]. Subsequently, the UHMWPE-g- $\mathrm{PO}_{4}$ fibers were washed with deionized water to remove $\mathrm{H}_{3} \mathrm{PO}_{4}$ adhered to the fibers, and dried at $60^{\circ} \mathrm{C}$ overnight under a vacuum. The density of phosphate groups $\left(\mathrm{D}_{\mathrm{PO}}, \mathrm{mmol} \cdot \mathrm{g}^{-1}\right)$ was determined by Equation (6):

$$
\mathrm{D}_{\mathrm{PO}}=\left(\mathrm{W}_{\mathrm{PO}}-\mathrm{W}_{\mathrm{g}}\right) \times 1000 /\left(98 \times \mathrm{W}_{\mathrm{PO}}\right)
$$

where $\mathrm{W}_{\mathrm{PO}}$ is the weight of UHMWPE-g- $\mathrm{PO}_{4}$ fibers, and the factor 98 is the molecular weight of $\mathrm{H}_{3} \mathrm{PO}_{4}$.

\subsection{Characterization}

ATR-FTIR spectroscopy was used to characterize the chemical structures of UHMWPE fibers. The spectra were acquired from a Bruker Tensor 27 FT-IR spectrometer, ranging from 600 to $4000 \mathrm{~cm}^{-1}$, by averaging 32 scans at a resolution of $4 \mathrm{~cm}^{-1}$. The chemical composition of the UHMWPE fibers was measured by XPS, performed with a Thermo SCIENTIFIC ESCALAB 250Xi instrument (Thermo Fisher Scientific Inc., Waltham, MA, USA) using monochromatic $\mathrm{Al} \mathrm{K \alpha}$ radiation. The surface morphologies of the graft-modified UHMWPE fibers were observed using SEM (FEI Quanta-250, Hillsboro, OR, USA) under an electron acceleration voltage of $20 \mathrm{kV}$ after sputtering with a thin layer of gold.

\subsection{U(VI) Sorption Tests}

\subsubsection{Sorption Kinetics}

$0.2 \mathrm{~g}$ of fiber sorbent was immersed in $1 \mathrm{~L}$ of $\sim 20 \mathrm{mg} \cdot \mathrm{L}^{-1} \mathrm{U}(\mathrm{VI})$ carbonate solution containing $2 \mathrm{~g} \cdot \mathrm{L}^{-1}$ of NaF. The mixture was shaken using a rotary shaker at $25^{\circ} \mathrm{C}$ and $100 \mathrm{rpm} .1 \mathrm{~mL}$ aliquots were taken from the solution at appropriate time intervals. The $\mathrm{U}(\mathrm{VI})$ concentrations for $0,1,3,6,12,24$, $48,72,96,120$, and $144 \mathrm{~h}$ in the resulting solutions were analyzed by a Perkin-Elmer Optima 8000 DV inductively coupled plasma optical emission spectrometry (ICP-OES) instrument (PerkinElmer Inc., Waltham, MA, USA). The U(VI) sorption capacity $\mathrm{Q}_{\mathrm{t}}\left(\mathrm{mg} \cdot \mathrm{g}^{-1}\right)$ and the removal ratio were determined by Equations (7) and (8), respectively:

$$
\begin{gathered}
\mathrm{Q}_{\mathrm{t}}=\left(\mathrm{C}_{0}-\mathrm{C}_{\mathrm{t}}\right) \times \mathrm{V} / \mathrm{m}, \\
\text { removal ratio }=\left(\mathrm{C}_{0}-\mathrm{C}_{\mathrm{t}}\right) \times 100 / \mathrm{C}_{0},
\end{gathered}
$$

where $\mathrm{C}_{0}$ is the initial $\mathrm{U}(\mathrm{VI})$ concentration, $\mathrm{C}_{\mathrm{t}}$ is the $\mathrm{U}(\mathrm{VI})$ concentration at various times, $\mathrm{V}$ is the volume of solution, and $\mathrm{m}$ is the mass of sorbent used. 


\subsubsection{Sorption Isotherm}

A series of $\mathrm{U}(\mathrm{VI})$ carbonate solutions containing $2 \mathrm{~g} \cdot \mathrm{L}^{-1}$ of $\mathrm{NaF}$ were prepared with $\mathrm{U}(\mathrm{VI})$ concentrations in the range of $1-30 \mathrm{ppm}$ at $\mathrm{pH} \sim 9.6$. Sorbent $(0.2 \mathrm{~g})$ was added to each solution $(1 \mathrm{~L})$, and the trial was carried out for $144 \mathrm{~h}$ on a rotary shaker at $25^{\circ} \mathrm{C}$ and $100 \mathrm{rpm}$. The $\mathrm{U}(\mathrm{VI})$ concentration was analyzed by ICP-OES. The U(VI) uptake amount $\mathrm{Q}_{\mathrm{e}}\left(\mathrm{mg} \cdot \mathrm{g}^{-1}\right)$ was calculated from the concentration difference between the beginning and the sorptional equilibrium by Equation (9):

$$
\mathrm{Q}_{\mathrm{e}}=\left(\mathrm{C}_{0}-\mathrm{C}_{\mathrm{e}}\right) \times \mathrm{V} / \mathrm{m}
$$

where $\mathrm{C}_{\mathrm{e}}$ is the $\mathrm{U}(\mathrm{VI})$ concentration at equilibrium.

\subsubsection{Influence of Coexisting Anions and Sorbent Dosage on U(VI) Removal Ratio}

A series of $1 \mathrm{~L} \mathrm{U}(\mathrm{VI})$ carbonate solutions $\left(\sim 20 \mathrm{mg} \cdot \mathrm{L}^{-1}\right)$ containing various salts were prepared, and aliquots of fiber sorbent $(0.2 \mathrm{~g})$ were then added to each solution. In addition, a batch of $1 \mathrm{~L} \mathrm{U}(\mathrm{VI})$ carbonate solutions $\left(\sim 30 \mathrm{mg} \cdot \mathrm{L}^{-1}\right)$ containing $2 \mathrm{~g} \cdot \mathrm{L}^{-1}$ of NaF were prepared, and various dosages of sorbents were then immersed into the solutions. The above mixtures were all shaken using a rotary shaker at $25^{\circ} \mathrm{C}$ and $100 \mathrm{rpm}$. The $\mathrm{U}(\mathrm{VI})$ concentrations in the resulting solution before and after adsorption for $144 \mathrm{~h}$ were analyzed by ICP-OES. The U(VI) removal ratio was computed by Equation (8).

\subsubsection{Recyclability Evaluation}

After each adsorption cycle, the fiber sorbent was regenerated by $1 \mathrm{M} \mathrm{Na}_{2} \mathrm{CO}_{3}$ aqueous solution, which can effectively desorb the uranyl ions from the UHMWPE-g-PO $\mathrm{P}_{4}$ sorbents [21,30]. During the elution, $\sim 0.2 \mathrm{~g}$ of the fiber sorbent was immersed in $1 \mathrm{~L}$ of $\mathrm{Na}_{2} \mathrm{CO}_{3}$ aqueous solution with continuous shaking at $25^{\circ} \mathrm{C}$ and $100 \mathrm{rpm}$ for $24 \mathrm{~h}$. The fiber was then rinsed with deionized water, dried at $60^{\circ} \mathrm{C}$ under a vacuum, and used in the next adsorption cycle.

Author Contributions: Synthesis of Phosphate-Based Sorbent, R.L. and Y.L.; Characterization, Y.L. and M.Z.; Uranium Adsorption Experiments, R.L., Z.X. and H.M.; Writing-Original Draft Preparation, R.L.; Writing-Review \& Editing, Supervision, Project Administration, G.W.; Funding Acquisition, R.L. and G.W."

Acknowledgments: This research was funded by [the National Natural Science Foundation of China] grant number [11675247, 11605275].

Conflicts of Interest: The authors declare no conflict of interest.

\section{References}

1. Ladeira, A.C.Q.; Morais, A.C. Effect of ammonium, carbonate and fluoride concentration on the uranium recovery by resins. Radiochim. Acta 2005, 93, 207-209. [CrossRef]

2. Badawy, S.M.; Sokker, H.H.; Othman, S.H.; Hashem, A. Cloth filter for recovery of uranium from radioactive waste. Radiat. Phys. Chem. 2005, 73, 125-130. [CrossRef]

3. Shen, Y.L.; Wu, J.R.; Liu, Z.Y.; Wu, W.S. Environmentally friendlier approach to nuclear industry: Recovery of uranium from carbonate solutions using ionic liquids. Ind. Eng. Chem. Res. 2015, 54, 8624-8628. [CrossRef]

4. Li, B.; Sun, Q.; Zhang, Y.; Abney, C.W.; Aguila, B.; Lin, W.; Ma, S. Functionalized porous aromatic framework for efficient uranium adsorption from aqueous solutions. ACS Appl. Mater. Interfaces 2017, 9, 12511-12517. [CrossRef] [PubMed]

5. Kentish, S.E.; Stevens, G.W. Innovations in separations technology for the recycling and re-use of liquid waste streams. Chem. Eng. J. 2001, 84, 149-159. [CrossRef]

6. Alexandratos, S.D.; Zhu, X. High-affinity ion-complexing polymer-supported reagents: Immobilized phosphate ligands and their affinity for the uranyl ion. React. Funct. Polym. 2007, 67, 375-382. [CrossRef]

7. James, D.; Venkateswaran, G.; Prasada Rao, T. Removal of uranium from mining industry feed simulant solutions using trapped amidoxime functionality within a mesoporous imprinted polymer material. Microporous and Mesoporous Mater. 2009, 119, 165-170. [CrossRef] 
8. Tripathi, A.; Melo, J.S.; D’Souza, S.F. Uranium (VI) recovery from aqueous medium using novel floating macroporous alginate-agarose-magnetite cryobeads. J. Hazard. Mater. 2013, 246, 87-95. [CrossRef] [PubMed]

9. Duff, M.C.; Hunter, D.B.; Hobbs, D.T.; Fink, S.D.; Dai, Z.; Bradley, J.P. Mechanisms of strontium and uranium removal from high-level radioactive waste simulant solutions by the sorbent monosodium titanate. Environ. Sci. Technol. 2004, 38, 5201-5207. [CrossRef] [PubMed]

10. Gunathilake, C.; Górka, J.; Dai, S.; Jaronie, M. Amidoxime-modified mesoporous silica for uranium adsorption under seawater conditions. J. Mater. Chem. A 2015, 3, 11650-11659. [CrossRef]

11. Yue, Y.F.; Sun, X.G.; Mayes, R.T.; Kim, J.; Fulvio, P.F.; Qiao, Z.A.; Brown, S.; Tsouris, C.; Oyola, Y.; Dai, S. Polymer-coated nanoporous carbons for trace seawater uranium adsorption. Sci. China Chem. 2013, 56, 1510-1515. [CrossRef]

12. Carboni, M.; Abney, C.W.; Liu, S.; Lin, W. Highly porous and stable metal-organic frameworks for uranium extraction. Chem. Sci. 2013, 4, 2396-2402. [CrossRef]

13. Zhang, Y.; Liu, Z.; Fan, F.; Zhu, L.; Shen, Y. Extraction of uranium and thorium from nitric acid solution by TODGA in ionic liquids. Sep. Sci. Technol. 2014, 49, 1895-1902. [CrossRef]

14. Saito, T.; Brown, S.; Chatterjee, S.; Kim, J.; Tsouris, C.; Mayes, R.T.; Kuo, L.-J.; Gill, G.; Oyola, Y.; Jankeb, C.J.; et al. Uranium recovery from seawater: Development of fiber adsorbents prepared via atom-transfer radical polymerization. J. Mater. Chem. A 2014, 2, 14674-14681. [CrossRef]

15. Abney, C.W.; Mayes, R.T.; Saito, T.; Dai, S. Materials for the recovery of uranium from seawater. Chem. Rev. 2017, 117, 13935-14013. [CrossRef] [PubMed]

16. Gill, G.A.; Kuo, L.J.; Janke, C.J.; Park, J.; Jeters, R.T.; Bonheyo, G.T.; Pan, H.B.; Wai, C.; Khangaonkar, T.; Bianucci, L.; et al. The uranium from seawater program at the pacific northwest national laboratory: Overview of marine testing, adsorbent characterization, adsorbent durability, adsorbent toxicity, and deployment studies. Ind. Eng. Chem. Res. 2016, 55, 4264-4277. [CrossRef]

17. Dudarko, O.A.; Gunathilake, C.; Wickramaratne, N.P.; Sliesarenko, V.V.; Zub, Y.L.; Górka, J.; Dai, S.; Jaroniec, M. Synthesis of mesoporous silica-tethered phosphonic acid sorbents for uranium species from aqueous solutions. Colloids Surf. A 2015, 482, 1-8. [CrossRef]

18. Vivero-Escoto, J.L.; Carboni, M.; Abney, C.W.; de Krafft, K.E.; Lin, W.B. Organo-functionalized mesoporous silicas for efficient uranium extraction. Microporous and Mesoporous Mater. 2013, 180, 22-31. [CrossRef]

19. Yamabe, K.; Ihara, T.; Jyo, A. Metal ion selectivity of macroreticular chelating cation exchange resins with phosphonic acid groups attached to phenyl groups of a styrene-divinylbenzene copolymer matrix. Sep. Sci. Technol. 2001, 36, 3511-3528.

20. Chi, F.T.; Wang, X.L.; Xiong, J.; Hu, S. Polyvinyl alcohol fibers with functional phosphonic acid group: Synthesis and adsorption of uranyl (VI) ions in aqueous solutions. J. Radioanal. Nucl. Chem. 2013, 296, 1331-1340. [CrossRef]

21. Zou, Y.D.; Cao, X.H.; Luo, X.P.; Liu, Y.; Hua, R.; Liu, Y.H.; Zhang, Z.B. Recycle of U(VI) from aqueous solution by situ phosphorylation mesoporous carbon. J. Radioanal. Nucl. Chem. 2015, 306, 515-525. [CrossRef]

22. Das, S.; Pandey, A.K.; Athawale, A.A.; Natarajan, V.; Manchanda, V.K. Uranium preconcentration from seawater using phosphate functionalized poly(propylene) fibrous membrane. Desalin. Water Treat. 2012, 38, 114-120. [CrossRef]

23. Li, R.; Pang, L.J.; Ma, H.J.; Liu, X.Y.; Zhang, M.X.; Gao, Q.H.; Wang, H.L.; Xing, Z.; Wang, M.H.; Wu, G.Z. Optimization of molar content of amidoxime and acrylic acid in UHMWPE fibers for improvement of seawater uranium adsorption capacity. J. Radioanal. Nucl. Chem. 2017, 311, 1771-1779. [CrossRef]

24. Zhao, Y.N.; Wang, M.H.; Tang, Z.F.; Wu, G.Z. ESR study of free radicals in UHMWPE fiber irradiated by gamma rays. Radiat. Phys. Chem. 2010, 79, 429-433. [CrossRef]

25. Ladeira, A.C.Q.; Morais, C.A. Uranium recovery from industrial effluent by ion exchange-Column experiments. Miner. Eng. 2005, 18, 1337-1340. [CrossRef]

26. Wang, H.L.; Xu, L.; Hu, J.T.; Wang, M.H.; Wu, G.Z. Radiation-induced oxidation of ultra-high molecular weight polyethylene (UHMWPE) powder by gamma rays and electron beams: A clear dependence of dose rate. Radiat. Phys. Chem. 2015, 115, 88-96. [CrossRef]

27. Sharif, J.; Mohamad, S.F.; Othman, N.A.F.; Bakaruddin, N.A.; Osman, H.N.; Güven, O. Graft copolymerization of glycidyl methacrylate onto delignified kenaf fibers through pre-irradiation technique. Radiat. Phys. Chem. 2013, 91, 125-131. [CrossRef] 
28. Zhang, B.; Wang, S.; Fu, L.; Zhang, L. Synthesis and evaluation of 8-aminoquinoline-grafted poly(glycidyl methacylate) for the recovery of Pd(II) from highly acidic aqueous solutions. Polymers 2018, 10, 437. [CrossRef]

29. Rajini, A.; Nookaraju, M.; Reddy, I.A.K.; Venkatathri, N. Synthesis, characterization, antimicrobial and cytotoxicity studies of a novel titanium dodecylamino phosphate. J. Saudi Chem. Soc. 2017, 21, S77-S85. [CrossRef]

30. Kirishima, A.; Kimura, T.; Tochiyama, O.; Yoshida, Z. Speciation study on complex formation of uranium(VI) with phosphate and fluoride at high temperatures and pressures by time-resolved laser-induced fluorescence spectroscopy. Radiochim. Acta 2004, 92, 889-896. [CrossRef]

31. Rivas, B.L.; Maturana, H.A.; Villegas, S. Adsorption behavior of metal ions by amidoxime chelating resin. J. Appl. Polym. Sci. 2000, 77, 1994-1999. [CrossRef]

32. Anirudhan, T.S.; Deepa, J.R. Synthesis and characterization of multi-carboxyl-functionalized nanocellulose/ nanobentonite composite for the adsorption of uranium (VI) from aqueous solutions: Kinetic and equilibrium profiles. Chem. Eng. J. 2015, 273, 390-400. [CrossRef]

33. Nasef, M.M.; Güven, O. Radiation-grafted copolymers for separation and purification purposes: Status, challenges and future directions. Prog. Polym. Sci. 2012, 37, 1597-1656. [CrossRef]

34. Nasef, M.M.; Hegazy, E.-S.A. Preparation and applications of ion exchange membranes by radiation-induced graft copolymerization of polar monomers onto non-polar films. Prog. Polym. Sci. 2004, 29, 499-561. [CrossRef]

35. Oyola, Y.; Dai, S. High surface-area amidoxime-based polymer fibers co-grafted with various acid monomers yielding increased adsorption capacity for the extraction of uranium from seawater. Dalton Trans. 2016, 45, 8824-8834. [CrossRef] [PubMed]

36. Wang, C.Z.; Lan, J.H.; Zhao, Y.L.; Chai, Z.F.; Wei, Y.Z.; Shi, W.Q. Density functional theory studies of $\mathrm{UO}_{2}{ }^{2+}$ and $\mathrm{NpO}_{2}{ }^{+}$with carbamoylmethylphosphine oxide ligands complexes. Inorg. Chem. 2013, 52, 196-203. [CrossRef] [PubMed]

37. Shao, D.; Li, Y.; Wang, X.; Hu, S.; Wen, J.; Xiong, J.; Asiri, A.M.; Marwani, H.M. Phosphate-functionalized polyethylene with high adsorption of uranium(VI). ACS Omega 2017, 2, 3267-3275. [CrossRef]

38. Yuan, L.Y.; Liu, Y.L.; Shi, W.Q.; Lv, Y.L.; Lan, J.H.; Zhao, Y.L.; Chai, Z.F. High performance of phosphonate-functionalized mesoporous silica for $\mathrm{U}(\mathrm{VI})$ sorption from aqueous solution. Dalton Trans. 2011, 40, 7446-7453. [CrossRef] [PubMed]

39. Zeng, Z.; Yang, S.; Zhang, L.; Hua, D. Phosphonate-functionalized polystyrene microspheres with controlled zeta potential for efficient uranium sorption. RSC Adv. 2016, 6, 74110-74116. [CrossRef]

40. Sarafraz, H.; Minuchehr, A.; Alahyarizadeh, G.H.; Rahimi, Z. Synthesis of enhanced phosphonic functional groups mesoporous silica for uranium selective adsorption from aqueous solutions. Sci. Rep. 2017, 7, 11675. [CrossRef] [PubMed]

41. Nho, Y.C.; Kwon, O.H.; Chen, J. Introduction of phosphoric acid group to polypropylene film by radiation grafting and its blood compatibility. Radiat. Phys. Chem. 2002, 64, 67-75. [CrossRef]

Sample Availability: Samples of phosphate-based UHMWPE fiber are available from the authors.

(C) 2018 by the authors. Licensee MDPI, Basel, Switzerland. This article is an open access article distributed under the terms and conditions of the Creative Commons Attribution (CC BY) license (http:/ / creativecommons.org/licenses/by/4.0/). 